This PDF is a selection from a published volume from the National Bureau of Economic Research

Volume Title: Hard-to-Measure Goods and Services: Essays in Honor of Zvi Griliches

Volume Author/Editor: Ernst R. Berndt and Charles R. Hulten, editors

Volume Publisher: University of Chicago Press

Volume ISBN: 0-226-04449-1; 978-0-226-04449-1

Volume URL: http://www.nber.org/books/bern07-1

Conference Date: September 19-20, 2003

Publication Date: October 2007

Title: Different Approaches to Estimating Hedonic Indexes

Author: Saeed Heravi, Mick Silver

URL: http://www.nber.org/chapters/c0879 


\title{
Different Approaches to Estimating Hedonic Indexes
}

\author{
Saeed Heravi and Mick Silver
}

\subsection{Introduction}

Measurement bias in the U.S. Consumer Price Index (CPI) has been the subject of three major reports: the Stigler Committee (Stigler 1961); the Boskin Commission (Boskin et al. 1996); and the report by the Committee on National Statistics (2002), the Schultze panel. A major concern of all three reports was bias due to an inability of the CPI to incorporate properly the effects of changes in the quality of goods and services consumed. The primary mechanism in CPI methodology for controlling for the effects on price of quality changes is the matched-model method. A sample of items is selected in a price-reference (base) period, their prices are recorded in that period, and items are matched in subsequent periods so that the resulting price changes are untainted by quality changes; like is compared with like.

Two sources of bias may arise with this method. The first is that the matched sample ignores the prices of unmatched varieties, particularly

Saeed Heravi is a reader in the Quantitative Methods Group at Cardiff University. Mick Silver is a senior economist at the International Monetary Fund.

Elements of this study are part of a wider study funded by the U.K. Office for National Statistics (ONS). We are grateful to the ONS for permission to reproduce some of this work in the form of this paper. This paper should not be reported as representing the views of the ONS or the International Monetary Fund (IMF), its executive board, or any of its member governments. The views expressed in this paper are those of the authors alone. We acknowledge the help of David Fenwick (ONS), Adrian Ball (ONS), and Pat Barr (GfK Marketing) in this respect. David Scott-Johnson (Bureau of Labor Statistics), W. Erwin Diewert (University of British Columbia), and Jack Triplett (Brookings) provided particularly helpful advice on earlier drafts as did Ernst Berndt (MIT), who also helped with drafting. We are also grateful for other comments received, including those from Ana Aizcorbe (Bureau of Economic Analysis), Timothy Erickson (Bureau of Labor Statistics), Matthew Shapiro (University of Michigan), and two reviewers. 
new varieties introduced after the base period - what Triplett (2004) calls out-of-sample bias. As the matched sample becomes increasingly unrepresentative of the universe of varieties, such bias may increase (Silver and Heravi 2005). Griliches (1997) referred to the problem as being "too late":

[O]nce included in the [U.S.] CPI, a chosen model is not changed until it is rotated out (on average after five years in the sample) or until it disappears and has to be replaced. If old items had the same price history as new ones, this would not matter. But many durable goods, and some service providers whose market share is declining, do not reduce their prices. Rather, they exit. As a result observed price history is not representative of a more inclusive average price history. Also, the current rotation policy will miss a whole generation of items whose turnover is rapid, such as computer models. ... The big problem is that the new models are rarely compared with the old: Because the CPI does not use hedonics for PCs, it has no way to evaluate and incorporate the implicit price decline due to the appearance, successively, of the 386, 486, and Pentium models. (Griliches 1997, 170)

The second potential source of bias arises from the methods statistical offices use to estimate a continuing series of prices when items from the matched sample are no longer sold in subsequent periods. The price changes can be imputed by assuming they are the same as other goods in their class, or replacement items' prices may be used with or without an explicit adjustment for any difference in its quality, depending on its perceived comparability. If such assumptions or adjustments are wrong, this gives rise to Triplett's in-sample bias (Triplett 2004). Hedonic regressions have been considered best suited for quality adjustments by the Stigler, Boskin, and Schultze reports, though a more cautious stance was taken by the latter:

Hedonic techniques currently offer the most promising approach for explicitly adjusting observed prices to account for changing product quality. But our analysis suggests that there are still substantial unresolved econometric, data, and other measurement issues that need further attention. (Committee on National Statistics 2002, 6)

This paper examines alternative approaches to the use of hedonic indexes for CPI measurement in dynamic markets to explicitly adjust for insample and out-of-sample bias when both matched and unmatched data are used. Such indexes are distinguished in section 8.2.2 from hedonic adjustments to noncomparable replacements that only dip into the universe of models when a model is unavailable for matching. Hedonic indexes use a sample of all prices in the periods under comparison. The need for an evaluation of the methods for hedonic indexes requires emphasis. Many product markets are highly differentiated by brand and characteristics with rapid turnover of models. Monitoring the matched prices of, for ex- 
ample, near obsolete models of personal computers (PCs) while ignoring new models is unsuitable. Hedonic indexes are based on (representative samples of) prices of models in each period, some of which will be matched, but some will reflect the dynamic nature of the market. There are a host of such methods, and this paper contributes to the evidence on their nature and how they differ.

This study examines alternative methods for dealing with situations in which the matched-models method breaks down. The broad nature of hedonic indexes is outlined in section 8.2. Section 8.3 outlines thirty-six alternative methods and discusses their relative merits. These methods fall under three general approaches: (a) Hedonic imputation (HI) indexes, ${ }^{1}$ which rely on parameter instability for the measurement of price changes; (b) dummy time (variable) hedonic (DTH) indexes, which paradoxically constrain parameters between the periods to be the same; and (c) fixed effects model (FE) indexes, which are similar to DTH indexes but use dummy variables for individual models, as opposed to their characteristics, to control for quality changes. The breadth of the empirical work allows us to consider a number of research questions. We comment on the use of chaining, weighting, arithmetic versus geometric aggregation, parameter instability, base-current period spread, and the differences between and relative merits of the three approaches. Research issues and formulas are summarized in section 8.4.

Section 8.5 outlines the data for the study: monthly scanner data for three electrical consumer durables: washing machines, vacuum cleaners, and dishwashers. The data includes details of prices, sales and quality characteristics on about 43,000 observations representing over 10 million transactions. Section 8.6 discusses the results from the thirty-six measures for three products over two years, that is, 216 resulting index numbers. It employs a meta-analysis of this data to better establish the patterns from employing different index number formulations. This extends to an analysis of the spread of base to current-period HI indexes, an issue of interest given a recommendation by Pakes (2003) for the use of "Paasche-type" current period $\mathrm{HI}$ indexes that require hedonic estimates in only the base period.

\subsection{The Hedonic Approach}

\subsubsection{Theory}

The hedonic approach involves the estimation of the implicit, shadow prices of the quality characteristics of a product. A set of $\left(z_{k}=1, \ldots, K\right)$ price-determining characteristics of the models is identified and data over

1. Also referred to as "characteristic price indexes" (Triplett 2004). 
$i=1, \ldots, N$ models are collected. An hedonic regression equation of the price of model $i, p_{i}$, on its set of quality characteristics $z_{k i}$ is given by

$$
\ln p_{i}=\gamma_{0}+\sum_{k=1}^{K} \beta_{k} z_{k i}+\varepsilon_{i}=h\left(z_{i}\right)+\varepsilon_{i} .
$$

The $\beta_{k}$ are estimates of the marginal valuations the data ascribe to each characteristic. Rosen (1974) showed that they can be equated in economic theory to a mapping of the equilibriums in characteristic space of production possibility curves and indifference curves of specific distributions of optimizing consumers and producers with respective varying tastes and technologies. Rosen (1974), Griliches (1988), Triplett (1988), and Pakes $(2003)^{2}$ have argued that the derivatives of a hedonic regression should not be interpreted as either one of estimates of willingness to pay derivatives or cost derivatives, but arise from equilibriums processes (though see Diewert [2003] for a demand-based framework). Griliches $(1988,120)$ noted that:

My own view is that what the hedonic approach tries to do is to estimate aspects of the budget constraint facing consumers, allowing thereby the estimation of "missing" prices when quality changes. It is not in the business of estimating utility functions per se, though it can also be useful for these purposes. ... What is being estimated is the actual locus of intersection of the demand curves of different consumers with varying tastes and the supply curves of different producers with possible varying technologies of production. One is unlikely, therefore to be able to recover the underlying utility and cost functions from such data alone, except in very special circumstances.

Nerlove (2001) commented that Griliches and others would have gotten nowhere if they had paid careful attention to the formidable identification problems. Griliches justified his continued use of hedonic regressions in the light of the ambiguity in the interpretation of the coefficients from hedonic regressions on pragmatic grounds:

Despite the theoretical proofs to the contrary, the Consumer Price Index (CPI) "exists" and is even of some use. It is thus of some value to attempt to improve it even if perfection is unattainable. What the hedonic approach attempted was to provide a tool for estimating "missing" prices, prices of bundles not observed in the original or later periods. It did not pretend to dispose of the question of whether various observed differentials are demand or supply determined, how the observed variety of the

2. Pakes (2003) identified the hedonic price function as the sum of the marginal cost function and a function that summarizes the relationship between mark ups and characteristics. The coefficients can thus change when the characteristics of products or the distribution of consumer preferences change. Two implications arise: coefficients may change over timenew products will be directed to parts of characteristic space where mark ups had been high driving down the mark up-thus being "unstable." Second, and more contentiously, Pakes argues that there is no reason to expect the coefficients to be positive on desirable characteristics. 
models in the market is generated, and whether the resulting indexes have an unambiguous welfare interpretation. Its goals were modest . . .

All of this has an air of "measurement without theory" about it, but one should remember the limited aspirations of the hedonic approach and not confuse it with attempts to provide a complete structural explanation of the events in a particular market. (Ohta and Griliches 1975, 326-27)

The application of hedonic regression to automobile prices in Griliches (1961, 1964) and Adelman and Griliches (1961) revived the hedonic approach to the construction of price indexes. He revisited hedonic price index number methodology in Griliches (1971) with some notes on the state of the art. This early paper foreshadowed many of the current issues of concern and the empirical subject matter of this study. ${ }^{3} \mathrm{He}$ recognized the need for weighting in regression estimates:

Most of the analyses have used unweighted data on models, specifications, and prices. But at any point of time some manufacturers may offer models with characteristics in undesirable combinations and at "unrealistic" (from the consumer's point of view) relative prices. Such models will not sell very well and hence should also not be allowed to influence our argument greatly. There is no good argument except simplicity for the one-vote-per-model approach to regression analysis. (Griliches 1971, 325)

The argument extended to the time dummy approach "But even here, we should use a weighted regression approach, since we are interested in an estimate of a weighted average of the pure-price change . .." (Griliches 1971, 326). He noted further the need to investigate the empirical form of the relationship, commenting on the preferred use of semi-logarithmic form.

He also drew attention to the relative merits of the two main approaches to hedonic indexes, the hedonic imputation (or characteristic price index) and the dummy time variable index. The former comes in many forms depending on the choice of which period's basket of characteristics are held constant. Using base- and current-period characteristic baskets may well generate different results. He referred to this "Laspeyres-Paasche problem" and advocated the use of chaining to ameliorate such differences. Griliches (1971) also drew attention to a sample selectivity problem in such hedonic index number construction. By using constant base-period characteristics, "new" models that exist in the current period but not in the base period are excluded. Similarly, by using constant current-period characteristics, "old" models that exist in the base period but not in the current pe-

3. Also considered in the paper were the use of second-hand market prices, a subject of subsequent research in Berndt and Griliches (1993) and Berndt, Griliches, and Rappaport (1995), the importance of utility theory in quality adjustments for price-level measurement and the identification problem with regard to supply and demand of characteristics. 
riod are excluded. ${ }^{4} \mathrm{He}$ contrasted this index number approach with the time dummy variable hedonic index method and expressed concern about the latter. First, it constrains the estimated parameters on the characteristics to be the same. Second, it is not well articulated with the rest of the index number literature, and, finally, it is subject to the vagaries of sample selection due to a comparability problem with the models available in each of the periods compared. This study picks up on these self-same issues, albeit nearly forty years hence: weighting, arithmetic versus geometric aggregator, current- to base-period spread, chaining, and the time dummy versus HI method.

His empirical work over the years did not of course neglect such issues. More recent examples include Berndt and Griliches (1993) and Berndt, Griliches, and Rappaport (1995) who showed how price indexes for computers can be constructed in various ways to give different results. They considered alternative specifications of age, time, and vintage effects in hedonic regressions and the interpretation of their coefficients and showed that estimated quality-adjusted price indexes based on these varied specifications gave different answers. They also experimented with formulations that took account of the information on quantities to estimate Laspeyres, Paasche, and (Törnqvist) Divisia-type indexes. Much empirical evidence was also provided on the instability of parameter estimates, something we argue in the following and in more detail in Silver and Heravi (2007), that should influence the choice of method.

This study continues this tradition of experimenting with different formulations of hedonic indexes. It is necessary to show whether choice of method does matter, that is, whether different measures provide substantively different results. We also note that something can be said about the choice of preferred method: that weighted hedonic indexes are preferred to unweighted ones, that symmetric weights of a superlative form are preferred to asymmetric ones, that chained hedonic indexes reduce spread and are preferred when prices and quantity changes are relatively stable, with issues relating to the choice between the time dummy variable method and HI method also being considered in the following and more fully in Silver and Heravi (2007).

Further discussions of econometric issues and examples of empirical work can be found in Cole et al. (1986), Dulberger (1989), Gordon (1990), Griliches (1990), Triplett (1990), Arguea, Hsiao, and Taylor (1994), Silver and Heravi (2001), Kokoski, Waehrer, and Rozaklis (2001), Diewert (2002), Pakes (2003), and Triplett (2004).

\subsubsection{Alternative Methods and the Scope of the Study}

Statistical offices use the matched-models method for CPI measurement, whereby price collectors select a sample of models in a price refer-

4. However, a (geometric) mean of the two estimates would include all data. 
ence period 0 and then continue to collect prices of these same matched models in subsequent periods so that the prices of like are compared with like. When a model is missing because it is obsolete, the price collector may find a replacement of a comparable quality, in which case a direct price comparison may be made. If the replacement model is not directly comparable in quality, then the coefficients (or predicted value) from a hedonic regression may be used to make a quality adjustment so that the old and new (noncomparable) unmatched prices can be compared. Silver and Heravi (2003a) refer to this as patching and Pakes (2003) as hybrid indexes. However, patching can only make use of data outside of the matched sample when an item is missing. It may be that several new varieties are introduced in a month when there are few, if any, replacements. The likely atypical price changes of the new varieties will be ignored with patching. In dynamic markets with a high rate of model turnover, such as personal computers, there is a need to resample each month the models sold if the index is to cover a representative sample of what is purchased. The concern of hedonic indexes is to ensure changes in the average quality of the models purchased do not taint measured changes in their average price. Of course chain-linked, Divisia, matched indexes would incorporate some of the dynamic changes in the prices of goods of different qualities, but the hedonic approach was "more willing to carry the 'linking' idea further, across models that differed significantly in more than one dimension" (Griliches 1990, 191).

\subsection{The Methods}

In this section we outline thirty-six hedonic index methods. Their purpose is the same: to measure the aggregate change in price between period 0 and period $t$ of models of a product sold, all of which may not be comparable in quality between these periods. Indeed some old models may only exist in period 0 and new ones only in period $t$. The hedonic index methods outlined differ in many ways. In sections 8.3.1 to 8.3.5, the methods outlined are hedonic imputation (HI) methods in which estimates of the prices in the two periods of a constant basket of characteristics are used. For example, in the numerator of equation (2) are the estimated (predicted) prices using the coefficients from a hedonic regression estimated in period $t$, but applied to a period 0 set of characteristics, $h^{t}\left(z_{i}^{0}\right)$. In the denominator are the estimated prices using the coefficients from a regression estimated in period 0 , but again applied to a period 0 set of characteristics, $h^{0}\left(z_{i}^{0}\right)$. All that changes in the comparison is the estimated implicit price coefficients; the bundle of characteristics compared remains the same-constant period 0 ones. Equation (3) is similar to equation (2), but holds period $t$ characteristics constant, and equation (4) is the geometric mean of the two.

Equations (1) to (4) use unweighted geometric means of hedonic prices 
in the numerator and denominator. In section 8.3.2, their weighted, by expenditure share, counterparts are outlined. Of course, an alternative approach is to calculate unweighted and weighted hedonic indexes using arithmetic means of price relatives rather than geometric means, and these arithmetic formulations are outlined in sections 8.3.3 and 8.3.4, respectively. Section 8.3.5 outlines HI indexes that instead of holding either period 0 or period $t$ characteristics constant, hold a mean function of these characteristics constant.

Section 8.3.6 outlines a quite different approach, the DTH index, that uses data for the two time periods compared in a single hedonic regression estimate. It includes a dummy variable for the time period and the coefficient on the dummy variable is an estimate of the price change untainted by quality changes. In section 8.3.6, a fixed effects estimator is used in which a dummy variable is included for each model, rather than variables on its quality characteristics. The HI, DTH, and fixed effects estimator can take chained or direct fixed base or can be fully constrained. In the following, we outline these methods in further detail.

\subsubsection{HI Indexes-Unweighted Geometric Means}

The first approach is the HI method, which has the same formulation as equation (1), that is, separate hedonic regressions of the (log of price) of model $i$ on its quality characteristics $z_{k i}$ are estimated for the base and current periods. The coefficients from these regressions $\left(h^{0}\right.$ and $\left.h^{t}\right)$ are estimates of the implicit prices of the quality characteristics $\left(z^{0}\right.$ and $\left.z^{t}\right)$ for the base and current periods and will then be used to calculate the $\mathrm{HI}$ indexes. Four methods are outlined here. Base- and current-period direct HI indexes (each requiring hedonic regressions in both periods), a geometric mean of the two, and an indirect current period hedonic index requiring only a base-period regression. All methods outlined here use geometric means. The Bureau of Labor Statistics (BLS) uses the geometric meanthe Jevons index - at this elementary aggregation for much of the U.S. CPI (Dalton, Greenlees, and Stewart 1998). A semilogarithmic formulation of the DTH method is used in the following, which is consistent with a geometric mean. ${ }^{5}$

The unweighted geometric (Jevons) hedonic base-period index holds base period 0 characteristics constant under both base- and current-period prices. Consider a semilogarithmic hedonic function $\hat{p}_{i}^{0}=h^{0}\left(z_{i}^{0}\right)$ where $\hat{p}_{i}^{0}$ are estimated prices (excluding $\varepsilon_{i}$ in equation [1]) in period 0 with period 0 quality characteristics and $N^{0}$ observations using equation (1). The resulting unweighted (or, more precisely, equally weighted) Jevons hedonic baseperiod index, $P_{\mathrm{JHB}}$, is given by

5. Silver (2002) has shown that influence effects in the regression of outliers may distort the representativity of such indexes. 


$$
P_{\mathrm{JHB}}=\frac{\left[\prod_{i=1}^{N^{0}} h^{t}\left(z_{i}^{0}\right)\right]^{1 / N^{0}}}{\left[\prod_{i=1}^{N^{0}} h^{0}\left(z_{i}^{0}\right)\right]^{1 / N^{0}}}=\frac{\left[\prod_{i=1}^{N^{0}} h^{t}\left(z_{i}^{0}\right)\right]^{1 / N^{0}}}{\left(\prod_{i=1}^{N^{0}} \hat{p}_{i}^{0}\right)^{1 / N^{0}}} .
$$

It is a hedonic price comparison because the characteristics are held constant and a base-period one because they are held constant in this period. Some authors refer to this as Laspeyres or Laspeyres-type index. The terminology is misleading as weights have yet to be applied, and these weights may be current or base period. We refer to base- or current-period HI indexes when the characteristic set being valued is a base- or current-period one.

Consider the first term of equation (2). The prices in equation (2) can be considered as those predicted from a period 0 bundle of characteristics using both period $t$ and period 0 hedonic equations and then compared. The denominator is the geometric mean of predicted prices in period 0 . The numerator is hypothetical: it is the geometric mean of prices of tied bundles of period 0 characteristics evaluated at the characteristic prices estimated in period $t$. Of course a utility maximizing consumer in period $t$ would not purchase a period 0 bundle of characteristics, but choose more of those characteristics whose relative prices had fallen. The base-period HI index thus overstates, or is an upper bound on, its true theoretical cost-of-living index (COLI) as by measuring the cost of a fixed base period basket of characteristics, it does not allow for consumers substituting toward items or characteristics with below-average price changes. ${ }^{6}$ Consumers are not going to be worse off under a base-period imputation because they can always substitute away from the base-period bundle of characteristics and may be better off from doing so.

The unweighted geometric (Jevons) hedonic current-period index with constant current period characteristics is given by

$$
P_{\mathrm{JHC}}=\frac{\left[\prod_{i=1}^{N^{t}} h^{t}\left(z_{i}^{t}\right)\right]^{1 / N^{t}}}{\left[\prod_{i=1}^{N^{t}} h^{0}\left(z_{i}^{t}\right)\right]^{1 / N^{t}}}=\frac{\left(\prod_{i=1}^{N^{t}} \hat{p}_{i}^{t}\right)^{1 / N^{t}}}{\left[\prod_{i=1}^{N^{t}} h^{0}\left(z_{i}^{t}\right)\right]^{1 / N^{t}}}
$$

What is apparent from the first terms of equations (2) and (3) is that parameter instability is the essence of quality-adjusted price change measurement using $\mathrm{HI}$ indexes. All that changes are the estimated coefficients. It is also apparent from equation (3) that by holding the basket of characteristics constant in the current period $t$, the hedonic imputation will give too little emphasis to above-average price changes of characteristics. It will understate its theoretical COLI, while equation (2) will overstate it.

6. Hedonic base-period indexes are defined in economic theory as the ratio of the minimum expenditures required to maintain a base-period level of utility when the consumer faces $p_{t}$ and $p_{t-1}$ prices and tied bundles of quality characteristics $z_{t}$ and $z_{t-1}$ (Triplett 1988; Feenstra 1995; Diewert 2002). 
The geometric mean of base- and current-period HI indexes are argued by Diewert (2002) to be a suitable symmetric mean in this (and many other) contexts:

$$
P_{\mathrm{JHBC}}=\sqrt{P_{\mathrm{JHB}} P_{\mathrm{JHC}}}
$$

The indirect current-period HI method is calculated as a Jevons hedonic imputed quantity index divided into an index measuring the change in price to derive a Jevons hedonic current-period indirect price index:

$$
P_{\mathrm{JHCI}}=\frac{\left(\prod_{i=1}^{N^{t}} p_{i}^{t}\right)^{1 / N^{t}}}{\left(\prod_{i=1}^{N_{0}^{0}} p_{i}^{0}\right)^{1 / N^{0}}} \div \frac{\left[\prod_{i=1}^{N^{t}} h^{0}\left(z_{i}^{t}\right)\right]^{1 / N^{t}}}{\left[\prod_{i=1}^{N 0} h^{0}\left(z_{i}^{0}\right)\right]^{1 / N^{0}}}=\frac{\left[\prod_{i=1}^{N^{t}} h^{t}\left(z_{i}^{t}\right)\right]^{1 / N^{t}}}{\left[\prod_{i=1}^{N^{t}} h^{0}\left(z_{i}^{t}\right)\right]^{1 / N^{t}}}=P_{\mathrm{JHC}}
$$

Equation (5) is, of course, equivalent to equation (3) and is used by some statistical offices on the assumption that the geometric mean of predicted prices is equal to that of actual ones.

It is worth noting that what we are trying to achieve is to bring into the calculation models of different quality; more specifically, old models available in period 0 , but not period $t$, and new models available in period $t$, but not in period 0 . Assume the sample is matched, $z_{i}^{0}=z_{i}^{t}$ and $N^{t}=N^{0}=N$. In this case, for equations (2) and (3), and similarly for other base- and current-period indexes:

$$
P_{\mathrm{JHB}}=P_{\mathrm{JHC}}=\frac{\left[\prod_{i=1}^{N} h^{t}\left(z_{i}^{t}\right)\right]^{1 / N}}{\left[\prod_{i=1}^{N} h^{0}\left(z_{i}^{0}\right)\right]^{1 / N}}=\frac{\left(\prod_{i=1}^{N} p_{i}^{t}\right)^{1 / N}}{\left(\prod_{i=1}^{N} p_{i}^{0}\right)^{1 / N}}
$$

That is, the hedonic base- and current-period indexes for the matched samples of items with identical characteristics require no quality adjustment; they are the ratio of average prices (or average of relatives). ${ }^{7}$ Our problem is because samples are not matched.

\subsubsection{HI Indexes-Weighted Geometric Means}

Equations (2), (3), (4), and (5) are unweighted indexes. In the compilation of a CPI, weights are not used at the lowest level of aggregation, say, for individual models of washing machines, due to lack of data on expenditure shares though Balk (2002) has argued that they may be implicit in the sample design. However, it is axiomatic that were data on expenditure shares available, they should be used to weight the price changes. Because scanner data provides current- and base-period expenditure share weights $\left(s_{i}^{t}\right.$ and $s_{i}^{0}$ ) and allows regressions to be run on current- and base-period

7. Diewert (2002) establishes similar results for weighted versions of these indexes. It can be argued that there is a bias in the estimator for a geometric mean of predicted prices, and the mean of predicted prices may not be equal to one of actual prices. However, for practical purposes and of exposition, we assume here that they cancel. 
data, the unweighted HI indexes can be compared with their weighted counterparts. Because equations (2) and (3) are ratios of geometric means, their weighted counterparts use a geometric aggregator for consistency so that the effects of weights can be determined without being confused by functional form. The weighted indexes in the base and current periods are geometric Laspeyres and geometric Paasche indexes, and these are applied to the Jevons base- and current-period HI indexes, respectively:

The geometric Laspeyres base-period hedonic index,

$$
P_{\text {HB-GLas }}=\frac{\left[\prod_{i=1}^{N^{0}} h^{t}\left(\mathrm{z}_{t}^{0}\right)^{s_{i}^{0}}\right]}{\left[\prod_{i=1}^{N^{0}} h^{0}\left(\mathrm{z}_{i}^{0}\right)^{s_{i}^{0}}\right]}
$$

the geometric Paasche current-period hedonic index,

$$
P_{\text {HC-GPas }}=\frac{\left[\prod_{i=1}^{N^{t}} h^{t}\left(z_{i}^{t}\right)^{s_{i}^{t}}\right]}{\left[\prod_{i=1}^{N^{t}} h^{0}\left(z_{i}^{t}\right)^{s_{i}^{t}}\right]} ;
$$

and the counterpart to equation (4), the Törnqvist HI index,

$$
P_{\text {HBC-Törnq }}=\sqrt{P_{\text {HB-GLas }} P_{\text {HC-GPas }}} \text {. }
$$

\subsubsection{HI Indexes - Unweighted Arithmetic Means of Relatives}

We compare the unweighted and weighted geometric aggregators in equations (2) to (9) with their arithmetic relatives counterparts: ${ }^{8}$

The unweighted arithmetic (Carli) hedonic base-period index,

$$
P_{\mathrm{CaHB}}=\frac{\sum_{i=1}^{N^{0}} \frac{h^{t}\left(z_{i}^{0}\right)}{h^{0}\left(z_{i}^{0}\right)}}{N^{0}} ;
$$

the unweighted arithmetic (Carli) hedonic current-period index,

$$
P_{\mathrm{CaHC}}=\frac{\sum_{i=1}^{N^{t}} \frac{h^{t}\left(z_{i}^{t}\right)}{h^{0}\left(z_{i}^{t}\right)}}{N^{t}}
$$

and the geometric mean of unweighted Carli hedonic base-and currentperiod indexes,

$$
P_{\mathrm{CaHBC}-\mathrm{GM}}=\left(P_{\mathrm{CaHB}} \times P_{\mathrm{CaHC}}\right)^{1 / 2} .
$$

8. There is a further set of arithmetic hedonic indexes based on the ratio of arithmetic averages, that is, Dutot hedonic indexes as there are other formulations including harmonic mean hedonic indexes not considered here. For a Carli hedonic-base index, separate (linear) hedonic estimates would be required for each period as $P_{\mathrm{CaHB}}=\sum_{i=1}^{N} h_{i}^{t}\left(z_{i}^{0}\right) / h_{i}^{0}\left(z_{i}^{0}\right)=\sum_{i=1}^{N} h_{i}^{t}\left(z_{i}^{0}\right) / \hat{p}_{i}^{0} \neq \sum_{i=1}^{N}$ $h_{i}^{t}\left(z_{i}^{0}\right) / p_{i}^{0}$. Diewert (2002) and Silver and Heravi (2003a) have argued that $\hat{p}_{i}^{0}$ should be used and not $p_{i}^{0}$ since any misspecification error that removes a price from the hedonic surface would then be included in the numerator, but not in the denominator, thus leading to bias. 


\subsubsection{HI Indexes-Weighted Arithmetic Means of Relatives}

We can also compare the weighted geometric indexes in section 8.2.2, equations (7) to (9), to their arithmetic counterparts:

The Laspeyres hedonic base-period index,

$$
P_{\mathrm{HB}-\mathrm{Las}}=\sum_{i=1}^{N^{0}} s_{i}^{0}\left[\frac{h^{t}\left(z_{i}^{0}\right)}{h^{0}\left(z_{i}^{0}\right)}\right] ;
$$

the Paasche hedonic current-period index,

$$
P_{\mathrm{HC}-\mathrm{Pas}}=\sum_{i=1}^{N^{t}} s_{i}^{t}\left[\frac{h^{t}\left(z_{i}^{t}\right)}{h^{0}\left(z_{i}^{t}\right)}\right]
$$

and the Fisher hedonic index,

$$
P_{\text {HBC-Fisher }}=\sqrt{P_{\text {HB-Las }} P_{\text {HC-Pas }}} \text {. }
$$

As regards the preferred weighting, $s_{i}^{0}$ or $s_{i}^{t}$, both baskets and indexes are equally justifiable from a conceptual point of view. Laspeyres $\left(s_{i}^{0}\right)$ is widely used for the pragmatic reason that base-period expenditure weights are readily available. Laspeyres is likely to overstate price changes because its fixed base-period weights do not reflect the substitution of items with below-average price increases for those with above-average price increases. Similarly, Paasche understates its theoretical COLI counterpart. However, there exists a class of superlative indexes, to which the Fisher and Törnqvist (equations [9] and [15]) indexes belong, that use symmetric averages of both base- and current-period quantity information (Diewert 1990). Such indexes do not suffer from substitution bias and, moreover, can also be justified from an axiomatic and average fixedbasket approach (Diewert 1997). Following Boskin et al. (1996), the BLS introduced a trailing Fisher index in recognition of its superiority as a measure of a COLI. ${ }^{9}$ A "trailing" index is one not computed in real time because there is a time lag until the necessary information (current-period weights) are gathered. Yet once computed, it is useful in establishing the magnitude and direction of any difference between it and the index computed in real time.

All of the preceding methods can be used as fixed-or chained-base indexes. A fixed-base Laspeyres HI index, for example, would compare prices in the base period 0 and current period $t$, while a chained version would form binary links between succeeding periods combining them using successive multiplication.

9. Note that the Schultze panel could not reach agreement as to whether COLI or a costof-goods index (COGI) should be the preferred target (Committee on National Statistics 2002). 


\subsubsection{Mean Value Function for Hedonic Indexes}

A constant-characteristics HI index may be based on a mean value of the base- and current-period characteristics, say $\bar{z}_{i}=\left(z_{i}^{0} z_{i}^{t}\right)^{1 / 2}$. In such a case, equations (2) and (3) would become ${ }^{10}$

$$
\frac{\left[\prod_{i=1}^{N} h^{t}\left(\bar{z}_{i}\right)\right]^{1 / N}}{\left[\prod_{i=1}^{N} h^{0}\left(\bar{z}_{i}\right)\right]^{1 / N}}=\frac{\left(\prod_{i=1}^{N} p_{i}^{t}\right)^{1 / N}}{\left(\prod_{i=1}^{N} p_{i}^{0}\right)^{1 / N}}
$$

but this would only hold for matched samples. If models exist in period $t$ but not in 0 , and vice versa, then the left-hand side of equation (16) is a hybrid measure, the matched items being evaluated at $\bar{z}_{i}$ while the unmatched ones may be at $z_{i}^{0}$ or $z_{i}^{t}$ in the denominator and numerator, respectively. The equality in equation (16) would then not hold. ${ }^{11}$

\subsubsection{Dummy Time Hedonic (DTH) Indexes}

A second approach is the DTH variable method that, as with $\mathrm{HI}$ indexes, does not require a matched sample. ${ }^{12}$ The formulation is similar to equation (1) except that a single regression is estimated on the data in the two time periods compared, $i \in N^{t} \cap N^{0}$, the equation also including a dummy variable $\mathrm{D}^{t}$ being 1 in period $t$, zero otherwise:

$$
\ln p_{i}^{t}=\delta_{0}+\delta_{1} \mathrm{D}^{t}+\sum_{k=1}^{K} \beta_{k}^{*} z_{k i}^{t}+\varepsilon_{i}^{t}
$$

The coefficient $\delta_{1}$ is an estimate of the quality-adjusted price change between period 0 and period $t$. Specifically, it is an estimate of the change in (the logarithm of) price, having controlled for the effects of variation in quality via $\Sigma_{k=1}^{K} \beta_{k}^{*} z_{k i}^{t}$. The $\beta_{k}^{*}$ coefficients are each constrained to be the same over periods 0 and $t$.

Three versions of equation (17) are considered for both weighted and unweighted indexes. The weighted versions use a weighted least squares (WLS) estimator, with the weights being expenditure shares. Diewert (2002) shows the form the weights should take for the estimates to correspond to particular index numbers, and Silver (2002) shows how observations with undue influence affect the "representativity" of the weights.

10. Similarly defined unweighted arithmetic and weighted-geometric and weightedarithmetic baskets of characteristics can be defined. These can be placed in similarly defined unweighted and weighted HI indexes, (akin to Walsh and Marshall-Edgeworth formulas). An $\mathrm{HI}$ index is a family of indexes and can be defined for any average basket, such indexes differing from averages of the base- and current-period indexes.

11 . We can conceive of a measure that extrapolates $z_{i}^{t}$ or $z_{i}^{0}$ using $\bar{z}_{j} / z_{j}^{t}$ or $\bar{z}_{j} / z_{j}^{0}$ for $j$ matched items expected to have similar changes in characteristics.

12. See de Haan (2003) for a variant that uses matched data when available and the time dummy only for unmatched data - his double imputation method. 
A fixed-base dummy (time) variable hedonic regression comparing January with December, for example, would use data only for these two months, the coefficient on the dummy variable taking a value of 1 in December and 0 in January.

A rolling, chained-base dummy (time) variable hedonic regression for a January-December comparison would estimate separate fixed-base dummy variable indexes for the January-February index, the FebruaryMarch index, the March-April index, ..., the November-December index, and combine these "links" by successive multiplication.

A fully constrained dummy (time) variable hedonic regression is a single constrained regression for, say, January to December with dummy variables for each month, though this is impractical in real time as it requires data on future observations. The regressions constrain each of the quality $\beta_{k}$ coefficients to be the same across months. In restricting the slopes to be the same, the (log of the) price change between, say, periods 0 and $t$ can be measured at any value of $z$. Bear in mind the HI indexes outlined in the preceding sections estimate the difference between price surfaces with different slopes. As such, the estimates have to be conditioned on particular values of $z$, which gives rise to the two estimates considered: the base hedonic imputation using $z^{0}$ and the current-period HI using $z^{t}$. For the DTH method, the very core of the method is to constrain the slope coefficients to be the same, so there is no need to condition on particular values of $z$. The estimate usefully and implicitly makes symmetric use of base- and current-period data. ${ }^{13}$

\subsubsection{Fixed Effects (Panel) Estimator}

A fixed effects dummy (time) period regression (suggested by Diewert 2003) treats the data as if it were panel data - the observations are on cross sections of models over time. The regression equation effectively has on its right-hand side the usual dummy variables for time, but also dummy variables for each (but one reference) model in any month instead of the quality characteristics, thus allowing us to control more directly for model heterogeneity (see Aizcorbe [2003] for an application). The specification of

13. It is worth noting that Pakes (2003) is critical of the method on this very ground as he considers a proper index to be one that is an (upper) bound on the true price index, rather than an estimate of it. He argues that the coefficients might be expected to be unstable over time, and, thus, restricting the coefficients to be the same does not provide an estimate that is an (upper) bound. Yet it is well accepted that neither Laspeyres nor Paasche are conceptually superior, and a Fisher or other superlative index is preferable. The Paasche only has an advantage because it requires a single base-period hedonic equation to be estimated. But this is not only conceptually unjustified, it is inconsistent with the base Laspeyres formulation used. A Paasche imputation is neither a fixed-base period COGI, which forms the conceptual basis of many European CPIs, nor a good approximation to a Fisher COLI index, which is the conceptual base for the U.S. CPI. 
such a model would require a large number of dummy variables, and, to ease the computation, statistical software employ an equivalent, but much simpler, procedure. Each variable for model $i$ in period $t$ is subtracted from its mean over all periods $t$. The price deviations $\left(p_{i}^{t}-\bar{p}_{i}\right)$ for each model are regressed on the deviations of the explanatory dummy variables $\left(x_{i}^{t}-\bar{x}_{i}\right)$ for each model in each period $t$ with an adjustment for degrees of freedom (Davidson and Mackinnon 1993, 323). The fixed effect panel estimator is effectively based on data of deviations of price and deviations of the dummy variables on the models from their respective means, for a model over time.

Fixed-base-fixed effects indexes are estimated comparing, for example, January data directly with December for a December index based on January. However, if a model is unmatched in either month, its price $p_{i}^{t}$ subtracted from $\bar{p}_{i}$, and its dummy explanatory variable, is 0 . The estimator effectively estimates indexes for only matched data. For an index that compares January with December, a large number of models will not be available in December (January) that were in January (December). As shown by Silver and Heravi (2001), less data is lost in the matching if chained indexes are estimated. The fixed-base, fixed effects estimator is effectively the matched-models estimator. White, Berndt, and Monroe (2004) expand on this in some detail. They call this matched-model econometrics.

A chained-base fixed effects index compares January with February, February with March, ... November with December, the results being combined by successive multiplication. A chained fixed effect index would not necessarily include all of the data but is likely to include very much more than a fixed-base one. For example, for a model available from January to March, the chained index for April would include its price change for the January to February and February to March links, but exclude it for the March to April link. The direct fixed-based index for January to April would exclude it (Silver and Heravi 2005).

A fully constrained fixed effects index may well utilize more data than the chained version as models may appear and reappear in subsequent periods, allowing $\left(p_{i}^{t}-\bar{p}_{i}\right) \neq 0$ slightly more frequently.

\subsection{Research Methods and Issues}

\subsubsection{Methods and Research Questions}

Table 8.1 summarizes the formulas used in this study for all three approaches. The following are the research questions:

1. Is the spread of the base- to current-period $\mathrm{HI}$ index (say $P_{\mathrm{JHB}}$ to $P_{\mathrm{JHC}}$ ) large? If so, neither a current-period HI index nor a base-period HI index 
Unweighted geometric

HI indexes

Jevons hedonic base imputation

Jevons hedonic current imputation

Geometric mean of above

\section{Weighted geometric}

Geometric-Laspeyres - hedonic base imputation

Geometric-Paasche-hedonic current imputation

Törnqvist geo-mean - hedonic base/current imputation

Unweighted arithmetic

Carli hedonic base imputation

Carli hedonic current imputation

Geometric mean of above

\section{Weighted arithmetic}

Laspeyres hedonic base imputation

Paasche hedonic current imputation

Geometric mean of above (Fisher)

\section{Unweighted}

Unweighted binary comparisons

Unweighted fully constrained

\section{Weighted}

Weighted binary comparisons

Weighted fully constrained

\section{Unweighted}

Unweighted binary comparisons

Unweighted fully constrained

\section{Weighted}

Weighted binary comparisons Weighted fully constrained

$$
\begin{array}{ll}
P_{\mathrm{JHB}} & \mathrm{CP}_{\mathrm{JHB}} \\
P_{\mathrm{JHC}} & \mathrm{CP}_{\mathrm{JHC}} \\
P_{\mathrm{JHBC}}=\sqrt{P_{\mathrm{JHB}} P_{\mathrm{JHC}}} & \mathrm{CP}_{\mathrm{JHBC}}
\end{array}
$$

$P_{\text {HB-GLas }}$

$\mathrm{CP}_{\mathrm{HB}-\mathrm{GLas}}$

$P_{\mathrm{HC}-\mathrm{GPas}}$

$\mathrm{CP}_{\mathrm{HC}-\mathrm{GPas}}$

$P_{\text {HBC-Törnq }}$

$\mathrm{CP}_{\text {HBC-Törnq }}$

$P_{\text {СаHв }}$

$P_{\mathrm{CaHC}}$

$P_{\mathrm{CaHBC}-\mathrm{GM}}$

$\mathrm{CP}_{\text {CaHB }}$
$\mathrm{CP}_{\mathrm{CaHC}}$
$\mathrm{CP}_{\mathrm{CaHBC-GM}}$

$P_{\text {HB-Las }}$

$P_{\mathrm{HC}-\mathrm{Pas}}$

$P_{\mathrm{HBC}-\mathrm{F}}$

$\mathrm{CP}_{\text {HB-Las }}$

$\mathrm{CP}_{\mathrm{HC}-\mathrm{Pas}}$

$\mathrm{CP}_{\mathrm{HBC}-\mathrm{F}}$

Time dummy variable

$P_{\mathrm{TD}}$
$P_{\mathrm{TD}-\mathrm{FC}}$

$\mathrm{CP}_{\mathrm{TD}}$

$P_{\mathrm{TDW}}$

$\mathrm{CP}_{\mathrm{TDW}}$

Fixed effects

$P_{\text {TDW-FC }}$

$P_{\mathrm{FE}} \quad \mathrm{CP}_{\mathrm{FE}}$

$P_{\mathrm{FE}-\mathrm{FC}}$

$\mathrm{CP}_{\mathrm{FEW}}$

by itself is justifiable, ${ }^{14}$ and a symmetric average of the two is more appropriate.

2. Does chaining minimize the spread?

3. Does weighting matter?

4. Does the use of a geometric aggregator over an arithmetic one matter?

5. What governs the base- to current-period hedonic spread?

14. Both current-period and base-period HI indexes are equally justified. The former uses current period characteristics and the latter base-period characteristics and neither can be said to be right or wrong. The issue of choice only matters if the results - the spread - is large, in which case a symmetric average of the two should be used. 
6. Are the results from the DTH approach similar to those of the HI approach?

7. Does weighting for the DTH approach matter?

8. What benefits, if any, are there from using a fixed effects (panel) estimator, and how do the preceding results compare with matched-model indexes?

\subsubsection{Formula Choice, Changes in the Characteristic Mix, and Parameter Instability}

\section{In General}

We take it as axiomatic that weighted indexes are preferred to unweighted ones. Indexes that make symmetric use of information are preferred to those that do not (Diewert 1997). So for weighted HI indexes, Fisher (Törnqvist) is preferred to Laspeyres and Paasche (geometric), and for unweighted hedonic indexes, geometric means of base- and currentperiod HI indexes are preferred to their constituent elements. It is apparent from equations (2) and (3), and similar such formulas, that such differences are primarily dictated by the extent to which the characteristics change over time, that is $\left(z_{i}^{0}-z_{i}^{t}\right)$. But the further hedonic base- and current-period estimates are apart, the less justifiable is the use of an individual estimate and the less faith there is in a compromise geometric mean. ${ }^{15}$

For unweighted indexes, a geometric mean (Jevons) is preferred to an arithmetic mean (Carli) of price relatives. The latter is upward biased in its failure of the time reversal test, while the former can be justified under the more reasonable assumption of unitary elasticity and sampling with probability proportionate to expenditure shares (Dalton, Greenlees, and Stewart 1998; Balk 2002). Chained-base indexes are preferred to fixed-base ones, especially when samples degrade rapidly and spread is reduced. Some caution is advised when prices "bounce" as chained indexes can drift (Forsyth and Fowler 1981; Szulc 1983). We consider in the following the relative merits of HI indexes as against DTH indexes, though note here that the equivalence of the fixed (panel) effect method to matched data makes it less desirable compared with HI and DTH indexes that use all the data (Silver and Heravi 2005).

\section{On Parameter Stability and HI Indexes}

The issue of parameter stability has been raised as an area of concern to the application of hedonic indexes. There is some empirical evidence of such instability. Berndt and Rappaport (2001) found, for example, from 1987 to 1999 for desktop PCs, the null hypothesis of adjacent-year equality to be

15. As an estimate of a COLI index the spread is irrelevant as the need is to include substitution effects and Fisher meets this need. However, Laspeyres and Paasche answer meaningful questions and act as bounds on models of economic behavior that different consumers might pursue. The Fisher estimate with less dispersion is more satisfactory. 
rejected in all but one case. And for mobile PCs, the null hypothesis of parameter stability was rejected in eight of the twelve adjacent-year comparisons. Stability tests can also be undertaken within product areas (Berndt and Rappaport [2001] compared and found parameter instability between mobile and desktop PCs) and across countries (Heravi, Heston, and Silver [2003] tested and were unable to reject parameter stability for cross-country price). Aizcorbe (2003) showed for a study of Intel's microprocessor chips the parameters to be unstable over time (annual data 1993-1999) and the use of different period's constrained parameters to lead in some periods to quite different indexes, though the parameters used were estimated from data that extended outside of the periods of the price comparisons. This would argue for our only constraining parameters within the sample comparison, unlike the fully constrained model outlined in section 8.3.6.

It should be noted that parameter instability, that is, from $h_{i}^{0}\left(z_{i}^{0}\right)$ to $h_{i}^{t}\left(z_{i}^{0}\right)$ in, for example, equation (2), is the essence of the measure of price change; it is not the cause of spread. The cause of spread between equations (2) and (3) is the change in characteristic values. If the coefficients were stable, there would be no price change in either equation (2) or (3). The HI method allows them to be unstable to enable price change measurement. Yet it has entered the debate for a specific reason. Pakes (2003) had as his target index a base-period one and, using quarterly data on PCs between 1995 and 1999, found very slight differences between base- and currentperiod hedonic indexes. He concluded that it might be reasonable to use a current-period HI index for initial price index publications by government statistical agencies. ${ }^{16}$ Parameter instability is thus identified as a problem for one-sided bound estimation on the grounds that were the base-period slope and intercept parameters stable, they could serve as current-period estimates. But were slope and intercept parameters stable, the basis of the measure would have no useful meaning - it would denote no price change. ${ }^{17}$ Thus, for a target index that uses an average of baseand current-period information, we caution against the use of either estimate alone if the spread is large, something dictated by the change in characteristics.

\section{Dummy Time Hedonic Index Compared with HI Indexes}

While the change in the slope coefficients is the essence of price measurement for HI indexes, the DTH method paradoxically constrains these slope coefficients from the two periods to be the same. The problem with

16. Pakes (2003) also found evidence of severe instability for PCs with the null of equality of coefficients for a general model in which the fourth year, when Pentium II was launched, was constrained to be the same as the preceding three years being rejected with a $\chi^{2}$ of 61,000 for $v=18 \mathrm{df}$.

17. Of course if only slope coefficients were stable, an HI index would be equivalent to a DTH index. 
$\mathrm{HI}$ indexes is that they are conditioned on a given basket of characteristics, say, base or current period, resulting in more than one possible index. An index that is invariant to the choice of basket would be one whose parameters on the characteristics were the same (parallel) over the ranges of $z$ in multivariate space. Because, it can be argued, there is no reason to prefer period 0 estimates of the (marginal) valuations of the characteristics to period $t$ ones, constraining the parameters to be the same as in equation (17), is not unreasonable. Thus the intuition of averaging baskets, aside from having a physical manifestation, is no less restrictive than one of averaging (constraining to be the same) marginal valuations. Both $\mathrm{HI}$ indexes and DTH indexes rely on hedonic regressions for quality adjustment, and both make use of an averaging process, of base and current indexes in the former case and constrained parameters in the latter, to achieve a desired measure. There is, at least in these broad conceptual terms, ${ }^{18}$ little to choose between the two approaches (though see Silver and Heravi 2006).

The two approaches can be compared based on considerations from economic theory and their satisfaction of axioms. Diewert (2004, chapters 1518) shows how the economic and axiomatic approach supports the use of the Fisher index number formula, and these same considerations will carry over to support of a Fisher HI index. The approach has the further advantage of giving an insight into the spread of the base- and current-period hedonic imputation estimates so that the reliability of an individual average estimate can be gauged. ${ }^{19}$ But functional forms for time dummy hedonic regressions, particularly the semilogarithmic, have also been shown (Diewert 2002) to possess good axiomatic properties.

Silver (2002) has shown that while HI indexes explicitly incorporate weights, they are implicitly incorporated in the ordinary least squares (OLS) or WLS estimator used for DTH. The latter may not be fully representative being subject to influence effects from observations with high leverage and residuals. Silver (2002) has also shown that adverse leverage effects are generated by observations with unusual characteristics and,

18. Some care is needed in the specification of the regressions for a correspondence of the approaches. For example, Diewert (2002) shows that for matched data an average of revenue shares over the two periods should be used as weights in a WLS estimator and for unmatched data the square root of the revenue share in the relevant period, if a correspondence with a Törnqvist index is desired.

19. Diewert (2002) points out that the main advantage of HI indexes is that they are more flexible, that is, changes in tastes between periods can readily be accommodated. Yet hedonic imputations are argued to have a disadvantage that $t w o$ distinct estimates will be generated, and it is somewhat arbitrary how these two estimates are to be averaged to form a single estimate of price change. Yet a Fisher average is generally supported axiomatic grounds. Diewert (2002) rightly identifies the main advantages of the dummy variable method as being that it conserves degrees of freedom and is less subject to multicollinearity problems. In this study, we are fortunate that degrees of freedom are not an issue given the relatively large sample size. We are careful to make our quality adjustments using predicted values rather than individual coefficients to avoid bias from multicollinearity. 
again, deficiencies in measures can be attributed to characteristic mix changes. We now turn to empirical evidence on the differences between the formulas summarized in table 8.1.

\subsection{Preliminary Empirical Analysis}

\subsubsection{Data: Scope and Coverage}

This study uses British scanner data on a monthly basis for the two year period 1998 and 1999 for three consumer durables: washing machines, vacuum cleaners, and dishwashers. Scanner data are compiled from the scanner (bar-code) readings of retailers. The electronic records of almost all transactions include the transaction price, time of transaction, place of sale, and a model number code for the item sold, which is linked to a file on the characteristics of the model. The transactions are counted and prices aggregated for each model sold in each outlet-type in each month (the data being supplemented by visits to independent outlets without scanners) to yield the volume, total value of sales, and, thus, the unit value or "price" of each model in each month or outlet-type. The observations are for a model of the product in a given month in one of four different outlet types: multiples (chains), mass merchandisers, independents, and catalog. Hedonic regressions are estimated to derive, for each month, coefficients on brands, characteristics, and outlet-types.

The coverage of the data is impressive both in terms of transactions and features. For Great Britain, for example, in 1998, table 8.2 shows the data to cover about 3 million transactions for vacuum cleaners. The coverage of outlets is estimated (by GfK Marketing Services) to be "well over 90\%," with scanner data being supplemented by data from price collectors in outlets that do not possess bar-code readers. The number of observations is given for each product in table 8.2 for 1998 and 1999, there being, for example, 9,043/12 - about 750 models of vacuum cleaners sold in each month on average in 1998. However, these figures treat the same model sold in a different outlet-type as a separate observation as their prices may

Details of the data, annual, 1998 and 1999

\begin{tabular}{|c|c|c|c|c|c|c|}
\hline & \multicolumn{2}{|c|}{$\begin{array}{l}\text { No. of transactions } \\
\text { (millions) }\end{array}$} & \multicolumn{2}{|c|}{$\begin{array}{l}\text { No. of models by } \\
\text { outlet type } \\
\text { (observations) }\end{array}$} & \multicolumn{2}{|c|}{$\begin{array}{l}\text { Total sales value } \\
\text { (£ millions })\end{array}$} \\
\hline & 1998 & 1999 & 1998 & 1999 & 1998 & 1999 \\
\hline Dishwashers & 0.382 & 0.436 & 4,621 & 4,483 & 140 & 140 \\
\hline Vacuum cleaners & 3.077 & 3.174 & 9,043 & 9,378 & 420 & 420 \\
\hline Washing machines & 1.517 & 1.732 & 7,750 & 7,728 & 550 & 600 \\
\hline
\end{tabular}


differ. For example, in 1998 there were 9,043 observations on 4,088 models of vacuum cleaners; 7,750 observations on 3,426 models of washing machines; and 4,605 observations on 2,259 models of dishwashers. Each model of vacuum cleaner, washing machine, and dishwasher was, on average, in $2.21,2.26$, and 2.04 outlet-types, respectively. From table 8.2 the data for the three products can be seen to amount to 43,000 such observations representing 10.3 million transactions valued at $£ 2.27$ billion. The observations are by model in an outlet-type, so the data clearly delineates which model is sold in each transaction.

\subsubsection{Data: The Variables}

The set of performance characteristics naturally varies between products. They are given in the appendix and, in their dummy variable representation, can be seen to be particularly extensive. Common to just about all products is, first, volume, which is the sum of the transactions during the period. Many of the models sold in any month have relatively low sales. Second is price, which is the unit value (value divided by quantity) of a model sold in one of four outlet-types in a month. ${ }^{20}$

\subsubsection{The Hedonic Regressions}

The OLS regressions were estimated on a data set that excluded models with sales of thirty or less in any month and a minimal number of models with extreme prices arising from variables not included in the data, such as stainless steel washing machines. The choice of thirty was based on some experimentation. ${ }^{21}$ The loss in the number of observations was quite severe for washing machines from 7,750 to 3,957, while the loss in terms of the volume of sales was minimal, from 1.517 million to 1.482 million. The corresponding figures were dishwashers, 4,605 to 1,890 observations, 381.2 thousand to 358.5 thousand sales and vacuum cleaners, 9,043 to 5,367 observations, 3.077 million to 3.036 million sales. As should be apparent from the preceding, many of the models had often only a single transaction, being the end of an old line with relatively low average prices (Silver and Heravi 2005).

The OLS estimated regressions all fitted well using conventional criteria

20. The definition of unit values benefits from it being defined across outlet types as opposed to all outlets in general (Silver and Webb 2003). There is some potential bias in the leastsquares estimates of predicted prices. Suppose the average price of model $k$ in one of the outlet types is $p_{k}$ for $i=1, \ldots, m$ transactions. Following footnote 5 , let $\ln p_{j}=a+b x_{j}+u_{j}$, then $\ln \hat{p}_{j}=a+b x_{j}$ (in general, $p_{j}=\exp \left[h\left(x_{j}\right)+u_{j}\right] \cdot p_{k}=1 / m_{k} \Sigma_{i}^{m} \exp \left(a+b x_{j}+u_{j}\right)=1 / m_{k} \Sigma_{i}^{m}$ $\exp \left[h\left(x_{j}\right)+u_{j}\right]=1 / m_{k} \Sigma_{i}^{m} \exp \left[h\left(x_{j}\right)\right]\left(\exp \left(u_{j}\right)\right)$ and $\ln \left(p_{k}\right)=h\left(x_{j}\right)+\ln \left[1 / m_{k} \Sigma_{i}^{m} \exp \left(u_{j}\right)\right]$.

The second term on the right-hand side need not equal zero, and this is ignored in the hedonic regression. Furthermore, as $m_{k}$ may be related to $p_{k}$ the OLS regression may be subject to omitted variable bias. However, we first examined the means of the residuals and found them close to unity (results available from authors) and, second, employed a WLS estimator that took some account of $m_{k}$. Finally, because our index numbers use ratios of predicted values, any bias may well cancel.

21. The results were qualitatively similar for weaker constraints. 
such as $F$-tests rejecting the null hypothesis of all coefficients equaling zero, $\bar{R}^{2} \mathrm{~s}$ of around 0.85 , and individual coefficients having the expected signs and magnitudes (results available from authors). The details of each of the estimated regression equations in each month are not presented here for reasons of space. ${ }^{22}$

There is a technical issue to consider. The residuals from estimates from a semilogarithmic regression may be homoskedastic, but distributed lognormally. If so, they are biased and an adjustment of $1 / 2$ variance of the residuals is required (Van Garderen and Shah 2002). The effect was found to be minimal in this study, the standard errors being very small. For example, the effect for 1998 estimates using a fixed-base time dummy method was to lower the estimated monthly price fall by 0.001 percentage point.

\subsection{Results}

Table 8.3 presents the results for the thirty-six formulas for three products for 1998 and 1999, 216 indexes in all. Choice of formula does matter. The standard deviations of monthly inflation rates for 1998 and 1999 are, respectively, -0.210 and -0.242 , about half of their respective means of -0.391 and -0.473 . Bear in mind that a standard deviation of about onehalf its mean value implies, when the observations are normally distributed, that approximately 95 percent of observations will be within the mean price plus or minus its own value, which is a substantial level of dispersion. The multitude of measures and influences makes it not straightforward to evaluate the results. Table 8.4 presents the results of a metaanalysis from a linear OLS regression of the hedonic indexes on dummy variables of distinguishing factors.

\subsubsection{Why Hedonic Indexes Differ}

In this section, we explore why the formulas give different results. Such differences are explained in terms of the period, product, use of weights, aggregator (geometric versus arithmetic), method (HI versus DTH versus FE index), and periodicity of the comparison (chain versus fixed base). Underlying these differences are further analytical factors including the proportion of all available observations that are actually used and have leverage on estimates and the correlation between relative (characteristic) price and quantity changes. The latter is considered separately below.

The coefficient on the year 1999 in the first column of table 8.4 shows the compound monthly change in hedonic-adjusted prices for 1999 compared with 1998: a fall in 1999, on average, by a further 0.082 percentage points than for 1998. This decline was after controlling for the different index number formulations. Dishwasher prices fell by on average 0.087

22. Though they are available from the authors upon request. 


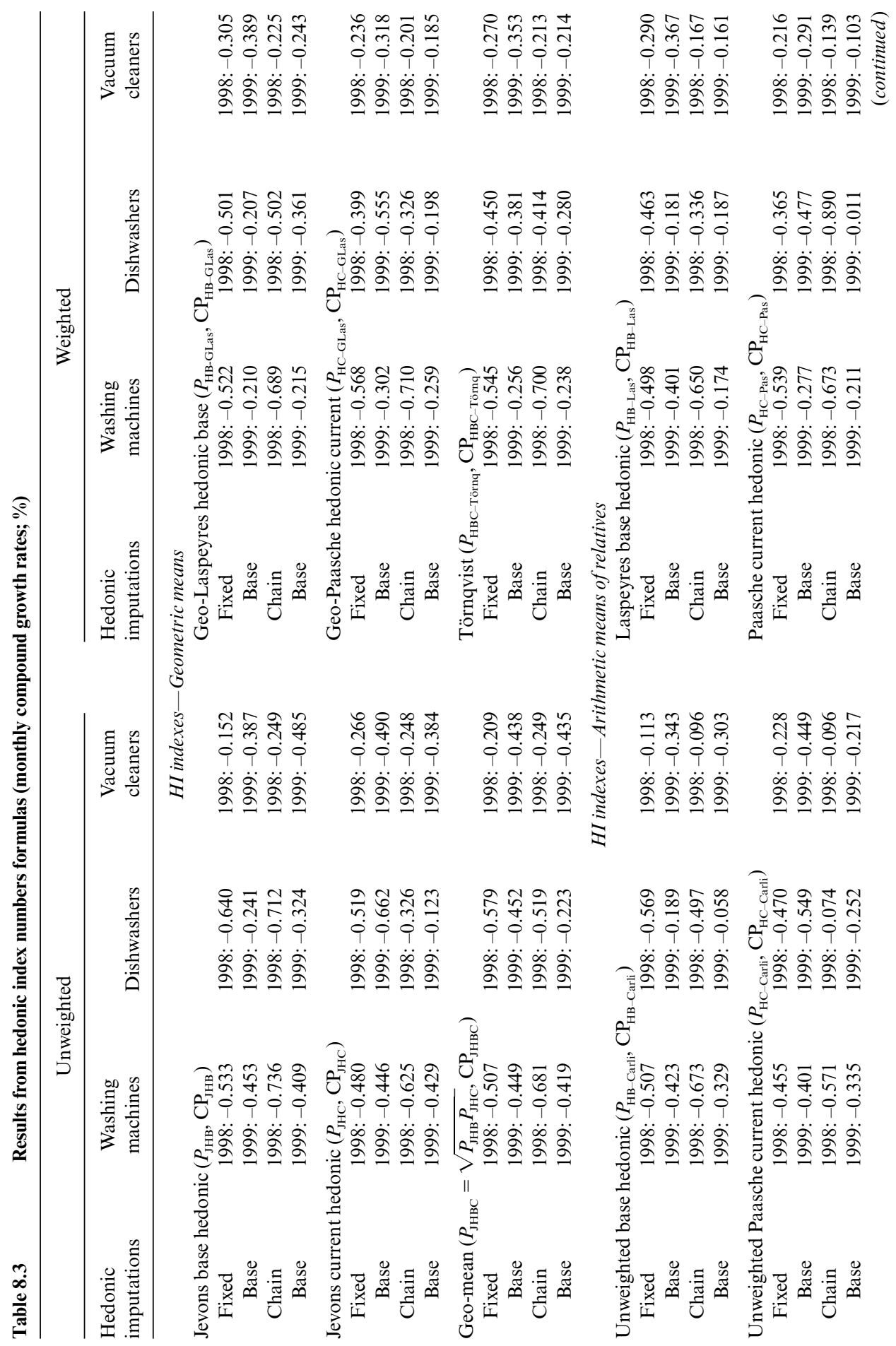




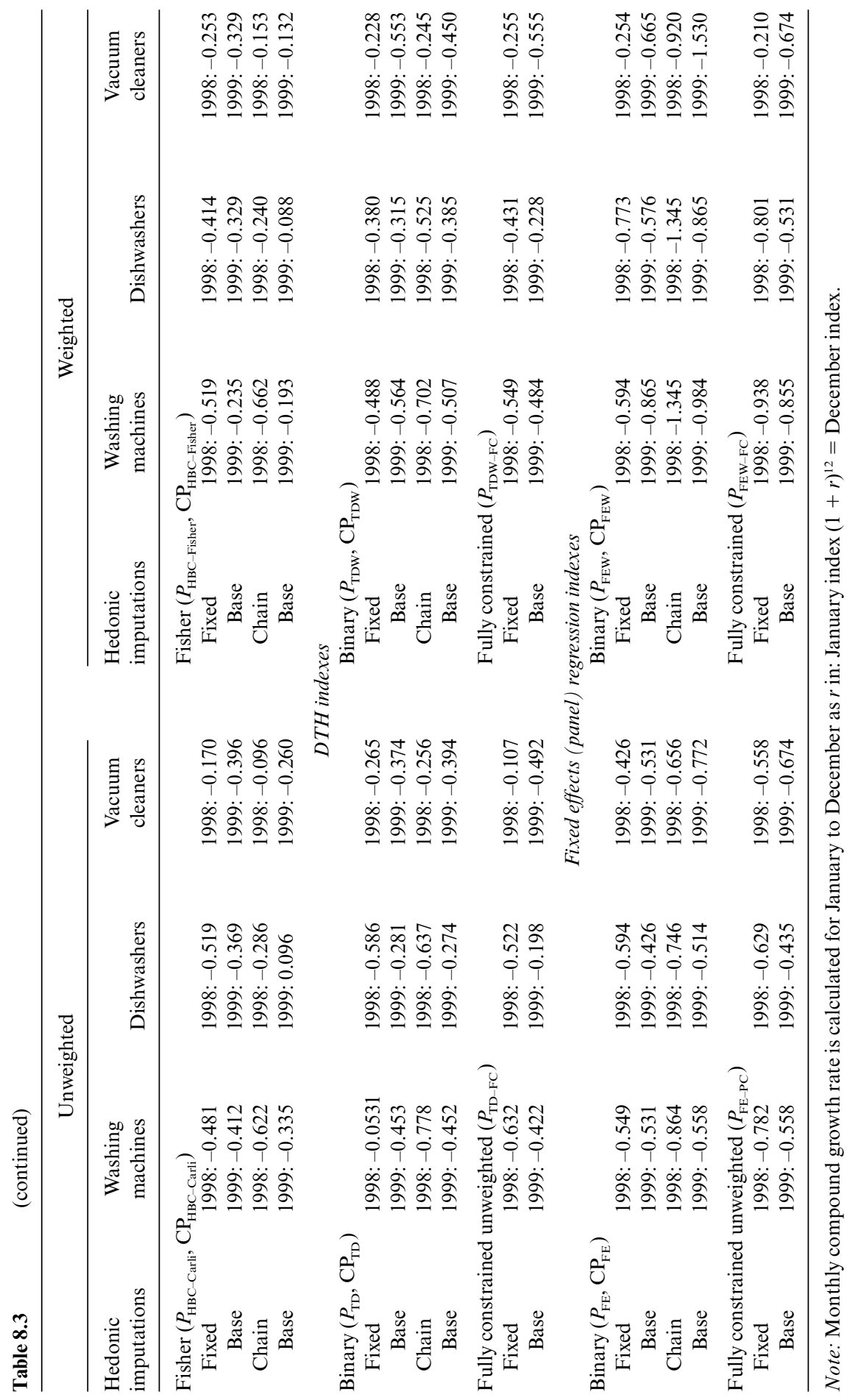


Meta-analysis regression of monthly compound hedonic inflation rates

\begin{tabular}{|c|c|c|c|c|c|c|}
\hline \multirow[b]{2}{*}{ Regression of: } & \multicolumn{2}{|c|}{ Hedonic indexes } & \multicolumn{2}{|c|}{ Spread (absolute values) } & \multicolumn{2}{|c|}{$\begin{array}{c}\text { Time dummy } \\
\text { less hedonic } \\
\text { imputation index } \\
\text { (absolute values) }\end{array}$} \\
\hline & Coefficient & $t$-statistic & Coefficient & $t$-statistic & Coefficient & $t$-statistic \\
\hline Intercept & -0.252 & $-6.58 * * *$ & 0.123 & $2.30^{* *}$ & 0.001 & 0.02 \\
\hline 1999 & -0.082 & $-3.63 * * *$ & 0.255 & $3.83^{* * *}$ & 0.003 & 0.07 \\
\hline Washing machines & -0.186 & $-6.69 * * *$ & 0.048 & 0.89 & 0.027 & 0.76 \\
\hline Dishwashers & -0.087 & $-3.12 * * *$ & 0.046 & 0.87 & 0.003 & 0.08 \\
\hline Chained & 0.105 & $4.17^{* * *}$ & -0.156 & $-2.31^{* *}$ & 0.099 & $2.21^{* *}$ \\
\hline Weighted & -0.008 & -0.34 & 0.007 & 0.16 & 0.061 & $2.11^{* *}$ \\
\hline Geometric-aggregation & -0.063 & $-2.28 * *$ & -0.085 & $-1.96^{*}$ & 0.005 & 0.19 \\
\hline Fixed effect $(\mathrm{FE})$ & -0.327 & $-8.26^{* * *}$ & & & & \\
\hline Time dummy hedonic (TD) & 0.041 & 0.75 & & & & \\
\hline $\mathrm{TD} \cdot$ chained & -0.160 & $-2.49 * *$ & & & & \\
\hline TD $\cdot$ weighted & -0.002 & -0.04 & & & & \\
\hline Geo-mean of indexes & 0.013 & 0.37 & & & & \\
\hline Current weighted & 0.003 & 0.07 & & & & \\
\hline$\overline{R^{2}}$ & \multicolumn{2}{|c|}{0.47} & \multicolumn{2}{|c|}{0.38} & \multicolumn{2}{|c|}{0.35} \\
\hline$N$ & \multicolumn{2}{|c|}{216} & \multicolumn{2}{|c|}{24} & \multicolumn{2}{|c|}{24} \\
\hline
\end{tabular}

***Significant at the 1 percent level.

**Significant at the 5 percent level.

percentage points more than vacuum cleaners and washing machines even further-by 0.186 percentage points more than vacuum cleaners. Chained indexes fell by on average 10.5 percentage points less than fixed-base ones, and weighted ones had no statistically significant difference to unweighted ones, after controlling for other features. We emphasize that these findings are for the overall average effect and that weighting can matter for some products (less so in 1998); for example, for washing machines in 1999, the unweighted geometric mean of geometric base and current period HI indexes fell by 0.449 percent, compared with a weighted Törnqvist index falling by 0.256 percent (table 8.3 ).

The use of geometric aggregation, as opposed to arithmetic aggregation, led to an on average further fall of 0.063 percentage points. The Fisher and Törnqvist hedonic indexes can be seen from table 8.3 to be fairly close in their fixed-base weighted form, but less so in their chained form and even less so in their unweighted formulations. ${ }^{23}$ The latter is because prices of poorly selling models decrease more rapidly than popular models. of the weighted aggregator but also in linear as against semilog functional form used for the hedonic imputations. 
The FE estimator was argued in the preceding to be implicitly constrained to matched samples, and its use had a more pronounced effecta further fall of 0.327 percentage points against other approaches. As identified earlier, the FE-fixed-base index implicitly only considers matched data between January and December, and the chained-base index is based on only matched successive binary comparisons. The fixed-base-FE matched-models estimator ignores, in any comparison between, say, January and December, the unmatched old models, available in January but unavailable in December. It also ignores the unmatched new models, available in December but unavailable in January. It is thus based on a more restrictive sample of data than the other indexes. The restriction is quite severe. Table 8.5 shows that for dishwashers, for example, just over half of the models available in January were no longer available in December 1998 for matching. Moreover, in December 1998 the matched sample had lost about 12 percent of the total January sales value (unmatched old models) and about 30 percent of the December sales value (unmatched new models; Silver and Heravi 2005). The chained-base indexes have clearly fallen more than their fixed-base counterparts, possibly due to the exclusion in the latter of many more unmatched new models with relatively low qualityadjusted prices.

There was no overall statistically significant difference between the DTH and $\mathrm{HI}$ indexes; the coefficient on the time dummy (TD) in table 8.3 of 0.041 compared with the benchmark HI was not statistically significant. However, in its chained form, this difference was statistically significant amounting to a quite substantial 0.16 percentage points. Table 8.3 reports substantial variation in the results for different DTH formulations; the chained form, for example, fell faster, by and large (or at a roughly equivalent rate) than the fixed-base index. The decision to use either of these three DTH formulations, given the discrepancies in results, argues for a clear idea of purpose. If it is to compare prices in a comparative static manner, not influenced by what went on in between, the fixed base is appropriate, otherwise the chained-path dependency or constrained aggregation is preferred.

Table 8.5

Summary of coverage of matched models, 1998

\begin{tabular}{lccc}
\hline & $\begin{array}{c}\text { Percentage of } \\
\text { January's observations }\end{array}$ & $\begin{array}{c}\text { Percentage of } \\
\text { January's sales value }\end{array}$ & $\begin{array}{c}\text { Percentage of } \\
\text { December's sales value }\end{array}$ \\
\hline December & 53.00 & Washing machines & \\
December & 55.86 & Dishwashers & 81.60 \\
December & 63.61 & Vacuum cleaners & 72.78 \\
& & 95.32 & 72.60 \\
\hline
\end{tabular}


It should be borne in mind that some of the HI indexes in the data are geometric means of other indexes, though their impact, other things being equal, is not statistically significant. A more important concern is the difference (coefficient on the dummy) between current-period hedonic imputations as against their base-period counterparts. Other things controlled for, this difference or spread is not statistically significant, but this is on average for a meta-analysis, and thus we consider spread in further detail in the following.

\subsubsection{The Spread between Base- and Current-Period HI Indexes}

The spread of individual results can be seen in table 8.3 to be quite substantial. We employed a similar meta-analysis to that used for all the index results, but on the (twenty-four absolute values of the) spread between the 48 current- and base-weighted formulas. The mean spread was 0.17 , with a standard deviation of 0.027 percentage points. The distribution was highly skewed as differences were more substantial than expected: for dishwashers in 1999, for example, the monthly average fall for the fixed-base HI index was 0.241 percent compared with 0.662 percent for the currentperiod HI index although other indexes had relatively small spread: the monthly average fall for washing machines was 0.453 , compared with 0.446 in 1999 for base- and current-HI indexes, respectively.

A regression (table 8.4) of the twenty-four differences found the (absolute) spread can change over time. In 1999 the spread was, on average, a substantial 0.255 percentage points more than its monthly amount in 1998 . A minimal spread in one period should not be expected to hold for the next. Chaining reduced the (absolute) spread by a considerable 0.156 percentage points, on average, and the use of a geometric mean aggregator further reduced such spread by 0.085 percentage points (though this was borderline statistically significant at the 5 percent level). An advantage of chaining is that it generally reduces spread as long as prices and quantity movements are smooth (see Forsyth and Fowler 1981; Szulc 1983).

\subsubsection{Differences between HI Indexes and Dummy Time Variable Hedonic (DTH) Indexes}

The mean and standard deviation of the absolute differences between the two methods was 0.09 and 0.018 percentage points, respectively. Table 8.3 shows that the results from the DTH approach often fell outside of the base- and current-period HI index bounds. Any differences between the approaches was argued in Section 8.4.3 to be in part positively associated with spread. Because spread was itself determined via the dummy variables that characterize the formulas (table 8.4), we regressed the difference between the DTH and HI indexes on such characteristics. Chaining and weighting were both found to increase the absolute value of the difference between the DTH results as against the HI ones (table 8.4). Chaining can 
be seen to be influential in all the regressions in table 8.4: it helps explain variation in hedonic indexes, spread, and the difference between DTH and $\mathrm{HI}$ indexes. There is a preference for chaining for the DTH approach as the restrictions on the coefficients to be the same over binary successive periods is not as severe as a fixed-base DTH restriction. There is also a preference for chaining if it reduces the spread in $\mathrm{HI}$ indexes. While the results suggest, to its merit, that chaining reduces spread in HI indexes, the increase in the difference between DTH and HI indexes is undesirable. The authors have undertaken research on factors relating to the difference between DTH and HI indexes to help resolve this (Silver and Heravi 2007) quandary. The difference arising from weighting is more problematic because on grounds of "representativity" we cannot argue for unweighted indexes. In table 8.4, weighting can be seen to have influence only with regard to the difference between DTH and HI indexes, and this may be due to the manner in which weights are used in the two formulations, in DTH indexes via WLS and explicitly in $\mathrm{HI}$ indexes. ${ }^{24}$

It is, of course, possible to say something about the best estimates. As noted in the preceding, superlative indexes are preferred to nonsuperlative ones and are known to approximate each other, so there is a strong case for Fisher or Törnqvist HI indexes and symmetrically weighted DTH indexes. Chaining is generally preferred to fixed-base indexes as it reduces the spread for $\mathrm{HI}$ indexes (as long as prices and quantities move smoothly) and requires less-severe restrictions for the coefficients from DTH regressions. Weighted indexes are generally preferred to unweighted ones.

\subsection{Summary}

The CPI measures aggregate changes in the prices of matched models of goods. The models are matched over time so that only pure price changes are measured, not those due to changes in quality. However, in many product markets, new models of different quality are introduced and old models discontinued. A CPI based solely on matched models would ignore these new and old models and not properly represent price changes. Hedonic regressions are a mechanism by which a valuation can be put on the quality components of a model of a good. Hedonic indexes allow aggregate price changes to be measured that include models of changing quality, that is, new and old unmatched models. As was argued in section 8.2, the need for hedonic indexes for the measurement of quality-adjusted prices is particularly acute in cases where there are differentiated products subject to a high turnover in models.

But hedonic indexes come in many forms. Further, the different forms

24. Silver (2002) showed that the weights implicit in a WLS estimator need not correspond to those explicitly used in an $\mathrm{HI}$ index because of influence effects. 
can give different results. The methods used in this study differ with regard to whether a chained formula or fixed-base index is used; a geometric as opposed to arithmetic mean; a fixed effect approach that only takes account of matched models, or one that uses all models; a DTH method as opposed to a HI method; and whether base-period, current-period, or some average of the two period's characteristics are held constant. There are many ways of using hedonic indexes.

In order to examine the extent of variation between methods and to try to explain such variability, this paper provides results on a meta-analysis of the 216 results (table 8.4) arising from examining thirty-six methods for constructing hedonic indexes for three products over each of two years, 1998 and 1999. A finding of the study is that the choice of method does matter; the standard deviations of monthly inflation rates for different methods for 1998 and 1999 are 0.210 and 0.242 , respectively, about half of their respective means of falls of 0.391 and 0.473 percent.

The meta-analysis reports smaller overall falls from chaining, larger falls from geometric aggregation and from the (matched) fixed effect approach. Of particular note is the substantial differences between chained DTH comparisons, which are built up by successive multiplication, from regression estimates over linked periods, say January with February, February with March, ..., November with December over fixed-base DTH ones that compare January directly with February, and then January directly with March, ..., December. When regression coefficients change over time, a case can be made for the use of chaining as fixed-base DTH indexes are more restrictive in their assumptions. Also of note is the quite substantial base- and current-period spread found in HI indexes. The extent of such spread is shown to be unstable over time (1998 compared with 1999) but could be reduced by chaining and employing a geometric aggregator. The result of substantial differences between HI indexes and DTH indexes is also of interest. The discussion in sections 8.4.2 and 8.4.3 implied there is little to choose between these approaches on theoretical grounds, which is cause for concern given the extent of the differences found. In particular, chaining was found to increase such differences arguing against its use from this standpoint.

The results of the paper are limited to British electrical domestic appliances and different patterns may emerge for other countries or product areas. Theory provides some guidelines as to which of these hedonic index formulations are preferred. As noted in the preceding section, there are good theoretical reasons to prefer symmetric averages or superlative formulations to base- or current-period ones, though often data are only available for asymmetric formulations. This study shows that the spread between the asymmetric base- and current-period formulations can be substantial. Chaining also has a good theoretical justification-unless prices and quantities do not move smoothly — and chaining should reduce 
the base- and current-period spread. The implicit restriction of the fixed effects estimator to matched data for binary comparisons argues against its use. However, the disparities between the two major approaches, DTH and $\mathrm{HI}$ indexes, remain of major concern and research on an analytical framework behind this difference is required (see Silver and Heravi 2007).

As regards further work, insights ${ }^{25}$ into the difference between index number formulas can be obtained by decompositions of the differences between such formulas. For example, ${ }^{26}$ the ratio of Paasche to Laspeyres price indexes $\left(P_{P}\right.$ and $\left.P_{L}\right)$ can be decomposed into an expression comprising the weighted coefficients of variation of price changes $\left(\sigma_{p} / P_{L}\right)$ and quantity changes $\left(\sigma_{q} / Q_{L}\right)$ and the weighted correlation coefficient $\left(r_{p: q}\right)$ between price and quantity changes:

$$
\frac{P_{L}}{P_{P}}=1+r_{p: q}\left(\frac{\sigma_{p}}{P_{L}} \frac{\sigma_{q}}{Q_{L}}\right)
$$

Details are provided in Allen $(1975,62)$, following a derivation in the 1922 and 1923 works of von Bortkiewicz and an application is in Abel, Berndt, and White (2003). However, first, such analysis is for matched price and quantity relatives, and our concern is with matched and unmatched data. Second, the prices and weights for indexes such as in equations (2) and (3) are prices and quantities of characteristics. Further research might look at how the Bortkiewicz decomposition may be applied to unmatched data and characteristic prices.

\section{Appendix}

\section{Characteristic Sets Included in Regression Formulations}

\section{Washing Machines}

(i) Manufacturer (make) — dummy variables for about twenty makes; (ii) type of machine: five types - top-loader, twin tub, washing machine (WM), washer dryer (WD) with and without computer, WD with or without condensers; (iii) drying capacity of WD; (iv) height of machines in centimeters; (v) width; (vi) spin speeds: five main-800rpm, 1,000rpm, 1,100rpm, 1,200rpm and 1,400rpm; (vii) water consumption; (viii) load capacity; (ix) energy consumption ( $\mathrm{kWh}$ per cycle); (x) free standing, built-

25. Alternatively the difference between some formulas can be phrased in terms of the dispersion of price relatives and economic theories relating to prices dispersion can be applied to explain such differences (Silver and Heravi 2003b).

26. Allen $(1975,186)$ also provides details of a decomposition of the difference between chained- and fixed-base Laspeyres. 
under and integrated, built-under not integrated, built-in and integrated; (xi) vintage; (xii) outlet types: multiples, mass merchandisers, independents, multiples; (xiii) vintage is the year in which the first transaction of the model took place.

\section{Dishwashers}

(i) Manufacturer (make) - dummy variables for about twenty-two makes; (ii) type of machine: four types-built-under, built-under integrated, table top, free standing; (iii) with microchip; (iv) width; (v) height; (vi) kWh per cycle; (vii) number of plates; (viii) number of programs; (ix) partly integrated, fully integrated, nonintegrated switch panel; $(\mathrm{x})$ water consumption; (xi) stainless steel; (xii) vintage; (xiii) outlet types: multiples, mass merchandisers, independents, multiples; (xiv) vintage is the year in which the first transaction of the model took place.

\section{Vacuum Cleaners}

(i) Manufacturer (make) — dummy variables for about twenty-nine makes; (ii) wattage; (iii) integrated or separate; (iv) remote control; (v) cord rewind; (vi) shampoo; (vii) speed control; (viii) soft or hard box; (ix) type of machine: six types - cylinder, upright, wet or dry, steam, handstick, rechargeable; (x) outlet types: multiples, mass merchandisers, independents, multiples.

\section{References}

Abel, J. R., E. R. Berndt, and A. G. White. 2003. Price indexes for Microsoft's personal software products. NBER Working Paper no. 9966. Cambridge, MA: National Bureau of Economic Research, September.

Adelman, I., and Z. Griliches. 1961. On an index of quality change. Journal of the American Statistical Association 56:535-48.

Aizcorbe, A. 2003. The stability of dummy variable price measures obtained from hedonic regressions. FEDS Working Paper no. 2003-05. Washington, DC: Board of Governors of the Federal Reserve System, February. http://www .federalreserve.gov/pubs/feds/2003/index.html.

Allen, R. D. G. 1975. Index numbers in theory and practice. London: Macmillan.

Arguea, N. M., C. Hasea, and G. A. Taylor. 1994. Estimating consumer preferences using market data: An application to U.S. automobile demand. Journal of Applied Economics 9:1-18.

Balk, B. M. 2002. Price indexes for elementary aggregates: The sampling approach. Statistics Netherlands Research Paper no. 0231. Voorburg, The Netherlands: Statistics Netherlands.

Berndt, E. R., and Z. Griliches. 1993. Price indexes for microcomputers: An exploratory study. In Price measurement and their uses, ed. Murray F. Foss, Marilyn E. Manser, and Allan H. Young, 63-93. Studies in Income and Wealth, vol. 57. Chicago: University of Chicago Press.

Berndt, E. R., Z. Griliches, and N. J. Rappaport. 1995. Econometric estimates of 
price indexes for personal computers in the 1990s. Journal of Econometrics 68:243-68.

Berndt, E. R., and N. J. Rappaport. 2001. Price and quality of desktop and mobile personal computers: A quarter-century historical overview. American Economic Review 91 (2): 268-73.

Boskin, M. J., E. R. Dulberger, R. J. Gordon, Z. Griliches, and D. W. Jorgenson. 1996. Toward a more accurate measure of the cost of living. Final report of the Advisory Commission to Study the Consumer Price Index. Washington, DC: Government Printing Office.

Cole, R., Y. C. Chen, J. A. Barquin-Stolleman, E. Dulberger, N. Helvacian, and J. H. Hodge. 1986. Quality-adjusted price indexes for computer processors and selected peripheral equipment. Survey of Current Businesses 65 (1): 41-50.

Committee on National Statistics. 2002. At what price? Conceptualizing and measuring cost-of-living and price indexes. Panel on Conceptual, Measurement and Other Statistical Issues in Developing Cost-of-Living Indexes, ed. Charles Schultze and Chris Mackie. Washington, DC: National Academy Press.

Dalton, K. V., J. S. Greenlees, and K. J. Stewart. 1998. Incorporating a geometric mean into the CPI. Monthly Labor Review 120 (10): 1-6.

Davidson, J. R., and J. G. Mackinnon. 1993. Estimation and inference in econometrics. New York: Oxford University Press.

Diewert, W. E. 1990. The theory of the cost-of-living index and the measurement of welfare change. In Price level measurement, ed. W. E. Diewert, 79-147. Amsterdam: Holland.

1997. Commentary for "Alternative strategies for aggregating prices in the CPI." Federal Reserve Bank of St. Louis Review 79 (3): 113-25.

2002. Hedonic regressions: A review of some unresolved issues. University of British Columbia, Department of Economics. Mimeograph.

- 2003. Hedonic regressions: A consumer theory approach. In Scanner data and price indexes, ed. Mathew Shapiro and Rob Feenstra, 317-48. Studies in Income and Wealth, vol. 61. Chicago: University of Chicago Press.

2004. Chapters 15 to 18. In Consumer price index manual: Theory and practice, 263-344. Geneva: International Labour Office. http://www.ilo.org/public/ english/bureau/stat/guides/cpi/index.htm.

Dulberger, E. 1989. The application of an hedonic method to a quality adjusted price index for computer processors. In Technology and Capital Formation, ed. D. W. Jorgenson and R. Londaus, 37-75. Cambridge, MA: MIT Press.

Feenstra, R. C. 1995. Exact hedonic price indexes. Review of Economics and Statistics 77 (4): 634-53.

Forsyth, F. G., and R. F. Fowler. 1981. The theory and practice of chain price index numbers. Journal of the Royal Statistical Society A 144 (2): 224-47.

Gordon, R. L. 1990. The measurement of durable goods prices. Chicago: University of Chicago Press.

Griliches, Z. 1961. Hedonic price indexes for automobiles: An econometric analysis of quality changes. Government Price Statistics: Hearings before the Subcommittee on Economic Statistics of the Joint Economic Committee. 87th Cong., January 24, 1961.

- 1964. Notes on the measurement of price and quality changes. In Models of income determination, 381-418. NBER Studies in Income and Wealth, vol. 28. Princeton, NJ: Princeton University Press.

1971. Hedonic price indexes revisited: Some notes on the state of the art. In Price indexes and quality change, ed. Z. Griliches, 3-15. Cambridge, MA: Harvard University Press.

1988. Postscript on hedonics. In Technology, education, and productivity, ed. Zvi Griliches, 119-22. New York: Basil Blackwell. 
1990. Hedonic price indexes and the measurement of capital and productivity: Some historical reflections. In Fifty years of economic measurement: The jubilee conference of research in income and wealth, ed. E. R. Berndt and J. E. Triplett, 185-202. Studies in Income and Wealth, vol. 54. Chicago: University of Chicago Press.

1997. The commission report on the consumer price index: Commentary. Federal Reserve Bank of St. Louis Review 79 (3): 169-73.

Haan, J. de. 2003. Time dummy approaches to hedonic price measurement. Paper presented at the seventh meeting of the International Working Group on Price Indices, Paris.

Heravi, S., A. Heston, and M. Silver. 2003. Using scanner data to estimate country price parities: An exploratory study. Review of Income and Wealth 49 (1): 1-22.

Kennedy, P. 1998. A guide to econometrics. Oxford, UK: Blackwell.

Kokoski, M., K. Waehrer, and P. Rozaklis. 2001. Using hedonic methods for quality adjustment in the CPI: The consumer audio products components. BLS Working Paper no. 344. Washington, DC: Bureau of Labor Statistics.

Nerlove, M. 2001. Zvi Griliches, 1930-1999: A critical appreciation. The Economic Journal 111 (472): 442-48.

Ohta, M., and Z. Griliches. 1975. Automobile prices revisited: Extensions of the hedonic hypothesis. In Household production and consumption, ed. N. Terleckyj, 325-91. Studies in Income and Wealth, vol. 40. New York: National Bureau of Economic Research.

Pakes, A. 2003. A reconsideration of hedonic price indexes with an application to PCs. The American Economic Review 93 (5): 1576-93.

Rosen, S. 1974. Hedonic prices and implicit markets: Product differentiation in perfect competition. Journal of Political Economy 82:34-55.

Silver, M. 2002. The use of weights in hedonic regressions: The measurement of quality-adjusted price changes. Cardiff University, Cardiff Business School. Mimeograph.

Silver, M., and S. Heravi. 2001. Scanner data and the measurement of inflation. The Economic Journal 11 (June): 384-405.

- 2003a. The measurement of quality-adjusted price changes. In Scanner data and price indexes, ed. Mathew Shapiro and Rob Feenstra, 277-317. Studies in Income and Wealth, vol. 61. Chicago: University of Chicago Press.

. 2003b. Why price index number formulae differ: Economic theory and evidence on price dispersion. In Proceedings of the 7th meeting of the (U.N.) International Working Group on Price Indices (Ottawa Group), ed. Thierry Lacroix, 175-212. Paris: INSEE. http://www.insee.fr/en/nom_def_met/colloques/ottawa/ pdf/paper_silver.pdf.

. 2005. Why the CPI matched models method may fail us: Results from an hedonic and matched experiment using scanner data. Journal of Business and Economic Statistics 23 (3): 269-81.

2007. The difference between hedonic imputation indexes and time dummy hedonic indexes. Journal of Business and Economic Statistics 25 (2).

Silver, M., and B. Webb. 2003. The measurement of inflation: Aggregation at the basic level. Journal of Economic and Social Measurement 28 (1-2): 21-36.

Stigler, G. 1961. The price statistics of the federal government. Report to the Office of Statistical Standards, Bureau of the Budget. New York: National Bureau of Economic Research.

Szulc, B. J. 1983. Linking price index numbers. In Price level measurement, ed. W. E. Diewert and C. Montmarquette, 537-66. Ottawa: Statistics Canada.

Triplett, J. E. 1988. Hedonic functions and hedonic indexes. In The new Palgrave's dictionary of economics, 630-634. New York: Macmillan.

-1990. Hedonic methods in statistical agency environments: An intellectual 
biopsy. In Fifty years of economic measurement: The jubilee conference on research in income and wealth, ed. E. R. Berndt and J. E. Triplett, 207-33. Studies in Income and Wealth, vol. 56. Chicago: University of Chicago Press.

. 2004. Handbook on quality adjustment of price indexes for information and communication technology products. Paris: Organization for Economic Cooperation and Development.

Van Garderen, K. J., and C. Shah. 2002. Exact interpretation of dummy variables in semi-logarithmic equations. Econometrics Journal 5:149-59.

White, A. G., J. R. Abel, E. R. Berndt, and C. W. Monroe. 2004. Hedonic price indexes for personal computer operating systems and productivity suites. NBER Working Paper no. 10427. Cambridge, MA: National Bureau of Economic Research, April. 